\title{
Impact of Plastic Packaging Materials and Storage Time on the Quality Parameters of Lebanese Extra Virgin Olive Oil under Real-Time Storage Conditions
}

\author{
Carla Zarazir 1,2, Mohamad Rajab',2, Houssam Obeid1,2, Joumana Toufaily1,2, Imad Toufeili³, \\ Tayssir Hamieh ${ }^{1,2^{*}}$ \\ ${ }^{1}$ Laboratory of Materials, Catalysis, Environment and Analytical Methods Laboratory (MCEMA), Lebanese University, \\ Hadath, Lebanon \\ ${ }^{2}$ Laboratory of Applied Studies to the Sustainable Development and Renewable Energies (LEADDER), EDST, \\ Lebanese University, Hadath, Lebanon \\ ${ }^{3}$ Department of Nutrition and Food Sciences, American University of Beirut (AUB), Beirut, Lebanon \\ Email: carla.zarazir@gmail.com,m.rajab@hotmail.fr, joumana.toufaily@ul.edu.lb, houssamobeid@hotmail.com, \\ toufeili@aub.edu.lb, *tayssir.hamieh@ul.edu.lb
}

How to cite this paper: Zarazir, C., Rajab, M., Obeid, H., Toufaily, J., Toufeili, I. and Hamieh, T. (2019) Impact of Plastic Packaging Materials and Storage Time on the Quality Parameters of Lebanese Extra Virgin Olive Oil under Real-Time Storage Conditions. American Journal of Analytical Chemistry, 10, 647-665.

https://doi.org/10.4236/ajac.2019.1012046

Received: November 13, 2019

Accepted: December 16, 2019

Published: December 19, 2019

Copyright $\odot 2019$ by author(s) and Scientific Research Publishing Inc. This work is licensed under the Creative Commons Attribution International License (CC BY 4.0).

http://creativecommons.org/licenses/by/4.0/

\section{(c) (i) Open Access}

\begin{abstract}
Scarce information is currently available relative to the use of polymeric materials as storage containers for extra virgin olive oil. This paper was devoted to study and compare the impact of glass and 3 types of packaging materials-polyethylene terephthalate (PET), high density polyethylene (HDPE), and polylactic acid (PLA) on Lebanese extra virgin olive oil (EVOO) up to 9 months under non-accelerated storage conditions. The acidity, peroxide value $(\mathrm{PV}), \mathrm{K}_{232}, \mathrm{~K}_{270}$, fatty acid profile, overall migration, and oil sorption into the packaging material were determined. Conventional titration, gas chromatography-mass spectrometry, and spectrophotometry were used to quantify the outcome measures at baseline, 3, 5, 7, and 9 months. Mixed model ANOVA was applied to assess differences according to polymer type and storage period at $P<0.05$. All quality parameters (acidity, $\mathrm{PV}, \mathrm{K}_{232}$ and $\mathrm{K}_{270}$ ), migration, and sorption significantly increased with increasing storage time for oil in contact with glass and plastic materials, especially between the 7th and 9th month of storage. Overall, PLA showed the least deterioration and interaction phenomena compared with PET and HDPE. While glass remains the best container for EVOO, PLA could potentially replace PET and HDPE for short-time storage under conventional storage conditions in Lebanese households.
\end{abstract}




\section{Keywords}

Extra Virgin Olive Oil, Polymer, Storage, Overall Migration, Fatty Acids

\section{Introduction}

Olive oil has been widely used for centuries in the Mediterranean diet for its distinctive organoleptic and nutritional characteristics [1] [2]. According to the Observatory of the International Olive Council [3], the global demand for olive oil has increased rapidly in the last 25 years, and the consumption share of countries that are not yet part of the IOC has practically tripled. Currently, large efforts are made to increase olive oil production worldwide, standardize trade, and establish common standards for olive oil chemistry. Among virgin olive oils fit for consumption and produced solely by mechanical means, the designation of EVOO corresponds chemically to a virgin olive oil with an acidity (percentage grams of free fatty acids (expressed as oleic acid) in 100 grams of olive oil) < $0.8 \%$, low peroxide value of less than 20 milliequivalent $\mathrm{O}_{2} / \mathrm{kg}$, low ultraviolet extinction coefficients $\mathrm{K}_{232}$ and $\mathrm{K}_{270}\left(\mathrm{~K}_{232} \leq 2.50, \mathrm{~K}_{270} \leq 0.22, \Delta \mathrm{K} \leq 0.01\right)$, and a high content of oleic acid (55\% to $83 \%$ ).

Several factors affect the quality of EVOO, including genetic (cultivar variety), agronomic (olive ripeness and harvest timing, irrigation, fertilization, and harvesting method), environmental (temperature, day length, and sunlight duration), geographical (cultivation area) factors, crop season, post-harvesting processing technique, packaging material and storage conditions (temperature, light and oxygen exposure, humidity, storage time) [4] [5]. Although EVOO is highly stable [6], it undergoes, from extraction to storage, oxidative and hydrolytic deterioration, termed "rancidity" attributed to lipid enzymatic hydrolysis and oxidation with partial loss of the oil characteristic sensory attributes and nutritional value [7]. These two naturally occurring and inter-related processes generate glycerol and free fatty acids (lipolysis) and peroxides from these fatty acids (primary oxidation). Peroxides are unstable compounds which are further oxidized to produce volatile and non-volatile components responsible for the off-flavors and undesirable aromas in the oil (secondary oxidation).

Storage material and conditions have a significant impact on the chemical quality, organoleptic properties and shelf life (defined as the length of time under normal storage conditions within which no off-flavors or defects develop and quality parameters are within accepted limits for this commercial category) [8] of EVOO. Storage containers should not only provide protection from air, light, and humidity, but also have no chemical interaction with the oil phase which can alter oil quality and its safety aspects. Trends in EVOO storage have shifted in the last decades from the traditional metal and glass containers to rigid plastics because of their light weight, cost-effectiveness, good resistance to mechanical damage, adaptability to several types of closures, and potential for per- 
sonalized design and color [4]. However, plastic packaging is associated with a number of disadvantages such as porosity and permeability to gases and vapours, migration of small molecular weight substances (additives, monomers, oligomers) by transient diffusion from plastic to oil, and sorption of components including volatile compounds and lipids into the packaging [9].

The most common rigid recyclable plastics approved by the Food and Drug Administration (FDA) for food contact are polyethylene terephthalate (PET) and high-density polyethylene (HDPE). PET belongs to the polyester family and is widely used as packaging material for edible oils due to its low permeability to water and oxygen, excellent mechanical properties, chemical inertness, dimensional stability, and lower price in comparison with glass [10] [11]. HDPE is a polyethylene thermoplastic made from petroleum and has a high strength-to-density ratio. In a study evaluating the impact of different packaging materials (PET, HDPE, glass, tin plates and pottery jars) on the chemical quality of Palestinian EVOO stored under different temperatures in a 6-month stability study [5], the authors demonstrated that at ambient storage temperature, the best container in maintaining the quality of EVOO was glass followed by HDPE, followed by both cans and PET, and the worst was pottery. At elevated temperatures, glass remained the best packaging material, followed by PET, cans, HDPE, and finally by pottery. When the effect of lighting conditions on the quality of EVOO was investigated in a 6-month period, the same group [7] reported that all packages maintained EVOO at the end of storage in terms of acidity, peroxide value, and $\mathrm{K}_{232}$. $\mathrm{K}_{270}$ exceeded the limit of EVOO in glass and PET-stored oil. Loss of phenols was the highest in glass- and the lowest in HDPE-stored oil. In extended illumination, HDPE bottles provided higher protection from oxidation when compared with PET and glass containers. However, under dark storage conditions, glass was superior to plastic in conserving EVOO.

In addition to the storage-related changes of the chemical properties and organoleptic characteristics of EVOO [1] [5] [7] [12], the interaction between EVOO and its packaging has been documented under accelerated and real-time conditions [10] [11] [13] [14]. Overall, the interaction between packaging and food combines two phenomena: migration and sorption. Migration refers to the transfer of non volatile chemical compounds from plastic packaging to foodstuffs [15] while sorption represents the penetration and dispersion of food compounds into the polymer matrix. The migrant molecules include polymerization residues (monomers, oligomers, solvents), stabilizers (pigments, additives, plasticizers), and printing inks. Sorption involves volatile organic components, fat, pigments, water vapour, and gases [16]. This diffusion process is influenced by several factors including temperature, time, and state of the polymer matrix [15].

In the last decade, polylactide (PLA), a new bio-based plastic packaging material, has started to replace traditional petro-based plastics as food industries have been devoted to the use of biodegradable materials to reduce the accumulation of plastics waste [10] [17]. Recently, PLA is being used as a food packaging 
polymer for short shelf life products such as containers, drinking cups and salad cups because it provided the excellent properties at a low cost as compared to other biodegradable polymers [17].

While several investigations have documented the impact of PET on EVOO quality during storage under real-time and accelerated conditions, scarce information is available relative to the changes occurring with HDPE and PLA packaging materials. The objectives of the present study were to evaluate and compare the impact of 3 types of plastic packaging (PET, HDPE, and PLA) on Lebanese EVOO up to a storage period of 9 months under real-time conditions that simulate conventional storage in Lebanese households. The outcome measures evaluated were: acidity, peroxide value (PV), $\mathrm{K}_{232}, \mathrm{~K}_{270}$, fatty acid profile, overall migration, and sorption of oil components into the packaging material.

\section{Materials and Methods}

\subsection{Samples Preparation}

\subsubsection{Olive Oil}

A 4-litre sample of EVOO produced in the crop year 2016 was obtained from a homogenous batch of olives (Olea europea) handpicked from trees located in Akkar (North Lebanon), cleaned from leaves and foreign materials, washed under running water, and processed by mechanical means using a traditional stone mill. Following malaxing/mixing of the olive paste, the oil phase was obtained by centrifugation using a three-phase decanter centrifuge without further filtration.

\subsubsection{Plastic Packaging}

Virgin transparent PET bottles (1.25 mm in thickness) and transparent HDPE bottles (2.1 $\mathrm{mm}$ in thickness) were procured directly from the industrial plant. Virgin clear PLA cups (1.15 $\mathrm{mm}$ in thickness) were shipped from France to Lebanon. The 3 packaging materials were cut into small rectangular pieces with scissors and using cotton gloves to avoid contamination of the plastic samples. The area of each test specimen was equal to $10 \mathrm{~cm}^{2}$.

\subsubsection{Experimental Design}

37 transparent glass jars of $300 \mathrm{cc}$ capacity and with metallic lids were sterilized and subsequently filled with $100 \mathrm{ml}$ of EVOO each leaving a headspace of $5 \mathrm{~cm}$ and one single piece of plastic was totally immersed in the EVOO in each container. For each storage interval (0, 3, 5, 7, and 9 months), three flasks with the same packaging material were prepared. One single reference flask of the same dimensions and containing $100 \mathrm{~mL}$ of EVOO without plastic was used as control. All sealed flasks were stored in the upper compartment of a dark closet in the kitchen under ambient temperature.

At the end of each aging interval, 9 interaction flasks -3 for each packaging material-were opened and the plastic samples removed for GC/MS (Gas Chromatography/Mass Spectrometry) sorption analysis according to the British Standard 2002 (NF EN 1186-2) [18]. Oil samples of different volumes were drawn from the flasks and evaluated for their chemical properties, fatty acid pro- 
file, and overall migration.

\subsection{Plastic Packaging-EVOO Interaction Tests}

\subsubsection{Chemicals Parameters of the EVOO}

Quality indices such as free acidity, given as the \% of oleic acid, peroxide value $(\mathrm{PV})$, and $\mathrm{K}_{232}$ and $\mathrm{K}_{270}$ extinction coefficients were measured using the analytical methods described in the European Union Standard methods (EC 2568/1991) [19]. The chemicals used were purchased from Sigma-Aldrich (USA).

\subsubsection{Acidity}

Briefly, $7 \mathrm{~g}$ of oil were dissolved in $50 \mathrm{~mL}$ solution of toluene $(20 \mathrm{~mL})$ and $95 \%$ ethanol $(30 \mathrm{~mL})$, and 2 drops of phenolphthalein ( $1 \%$ in ethanol) were added to the solution as indicator. The mixture was then titrated with $0.1 \mathrm{~N}$ potassium hydroxide $(\mathrm{KOH})$ previously standardised against hydrochloric acid $(\mathrm{HCl})$. The volume of titrant was recorded and the FFA content was calculated as a percentage of the oil (expressed as oleic acid).

\subsubsection{Peroxide Value}

$5 \mathrm{~g}$ of oil were dissolved in acetic acid/trichloromethane mixture (3:2). To this solution, $0.5 \mathrm{~mL}$ of saturated potassium iodide (KI) $(70 \mathrm{~g} \mathrm{KI} / 40 \mathrm{~mL}$ water) was added and shaken for one minute. Distilled water $(30 \mathrm{~mL})$ was added followed by approximately $0.5 \mathrm{~mL}$ of $1 \%$ starch solution $(1 \mathrm{~g}$ starch/100mL water). The mixture was titrated with previously standardized $0.1 \mathrm{~N}$ of sodium thiosulphate $\left(\mathrm{Na}_{2} \mathrm{~S}_{2} \mathrm{O}_{3}\right)$. The volume of titrant was recorded and the PV calculated and reported as $\mathrm{mEq}$ of active oxygen $/ \mathrm{kg}$ oil (meq $\left.\mathrm{O}_{2} / \mathrm{kg}\right)$.

\subsubsection{Ultraviolet Absorption Coefficients}

$0.25 \mathrm{~g}$ of oil was weighed into a $25 \mathrm{~mL}$ volumetric flask and made to volume with cyclohexane. The absorbance of the oil sample was measured on a double beam spectrophotometer (UV/VIS, Hitachi U-2900, Tokyo, Japan), using cyclohexane blank as a reference, at 232-, 266, 270-and 274-nm wavelengths. The UV absorbance was then calculated and reported as $\mathrm{K}_{232}$ and $\mathrm{K}_{270}$.

\subsubsection{Fatty Acid Composition}

A solution of EVOO in hexane $(0.2 \mathrm{~g}$ in $3 \mathrm{ml})$ with $0.4 \mathrm{ml}$ of $2 \mathrm{~mol} / \mathrm{l}$ methanolic potassium hydroxide was prepared and vigorously shaken. The mixture was left until stratification of the phases and then the upper layer containing the methyl-esters was decanted and subsequently analysed by GC/MS. For this purpose, a gas chromatograph coupled with a mass spectroscopy detector (GC-MS, Fisher Thermo Scientific, Milan, Italy) and a capillary column $(30 \mathrm{~m} \times 0.25 \mathrm{~mm} \times 0.25$ $\mu \mathrm{m}$, HP-5 MS, Fisher Thermo Scientific, Milan, Italy) were used under the following conditions: oven temperature ramp from $50^{\circ} \mathrm{C}$ to $250^{\circ} \mathrm{C}$ at a rate of $4^{\circ} \mathrm{C} / \mathrm{min}$; injector and detector temperatures $280^{\circ} \mathrm{C}$; and helium flow 0.8 $\mathrm{ml} / \mathrm{min}$; injection volume $2 \mu \mathrm{l}$; ionization electron energy $70 \mathrm{eV}$; ion source 
temperature of $150^{\circ} \mathrm{C}$; scanning range 50 - $300 \mathrm{amu}$; scan rate $1 \mathrm{~s} / \mathrm{scan}$. For each fatty acid, results were expressed as a percentage of relative area. Data was acquired and processed using the XCALIBUR software (v. 2.1.0.140, USA). Identification of compounds was based on a NIST 2.0 mass spectra library search. Prior to testing, the system was calibrated using different quantities of EVOO (5, $10,20,30,40$ and $50 \mathrm{mg}$ ) which were subjected to the same protocol as the samples. For each quantity of oil, the calibration graph was obtained plotting the calculated ratios (combined area of $\mathrm{C} 16$ and $\mathrm{C} 18$ peaks to the area of the internal standard) against the weighed quantities of EVOO.

\subsubsection{Sorption and Overall Migration}

Following removal of the plastic specimens from the EVOO flasks, the adhering oil was left to drip and the test pieces dried repeatedly between 2 sheets of Whatman No. 1 filter paper until the filter sheets were completely dry with no visible oil spots. The packaging samples were then transferred into $50 \mathrm{~mL}$ glass flasks. The extraction was performed by adding $30 \mathrm{~mL}$ of $\mathrm{n}$-hexane to the flasks under magnetic stirring at $50^{\circ} \mathrm{C}$ for $30 \mathrm{~min}$. This procedure was repeated twice with fresh solvent. Prior to the first extraction, $5 \mathrm{ml}$ of a solution of $2000 \mathrm{mgL}^{-1}$ of triheptadecanoin (internal standard) were added into each flask. Subsequently, the extracts were evaporated to dryness by means of a rotary evaporator (Heidolph, Germany). The residues were then dissolved in $10 \mathrm{~mL}$-hexane and hydrolized through the addition $10 \mathrm{~mL}$ of a solution of potassium hydroxide (11 $\mathrm{g} / \mathrm{L}$ ) in methanol under reflux. Methylation of the released fatty acids was carried out by adding $5 \mathrm{~mL}$ of boron trifluoride/methanol. Finally, the upper phase of the extracts was injected into the calibrated CG/MS machine under the same conditions as described above.

Overall migration was calculated based on the following equation:

$$
\left.M=\left[\left(m_{b}-m_{c}\right)-m_{a}\right)\right] / s
$$

where,

$M$ is the overall migration of plastic packaging material into EVOO $\left(\mathrm{mg} / \mathrm{dm}^{2}\right)$. $m_{a}$ is the initial mass in mg of the test specimen before contact with EVOO.

$m_{b}$ is the mass in $\mathrm{mg}$ of the test specimen after contact with oil.

$m_{c}$ is the amount in mg of absorbed oil determined by GC.

$s$ is the surface area of the plastic test specimen $\left(\mathrm{dm}^{2}\right)$.

\subsection{Statistical Analysis}

Descriptive statistics with mean values and standard deviations were obtained at each time interval for all parameters. Two-way mixed-model ANOVA and Bonferroni post hoc was used for multiple comparisons and interaction among the explanatory variables with the packaging material (glass versus HDPE versus PET versus PLA) as the between-subject effect and storage time (3 versus 5 versus 7 versus 9 months) as the within-subject effect. The Mauchly test was used to test the assumption of sphericity. In case of violation, the degrees of freedom were corrected using the Greenhouse-Geisser estimates. Statistical significance 
was set at $P<0.05$. The data were analyzed using the statistical software (IBM SPSS v 25; IBM Corp).

\section{Experimental Results and Discussion}

The baseline chemical parameters of the EVOO sample confirmed its categorization as EVOO according to the Regulations EEC/2568/91and EEC/2472/97 of the European Union Commission [19] [20]. Descriptive and comparative statistics of the chemical parameters according to the type of packaging and storage time are summarized in Tables 1-7.

Table 1. Descriptive statistics with means and standard deviations of acidity according to packaging material and storage time.

\begin{tabular}{ccccc}
\hline \multicolumn{5}{c}{ \% Acidity Mean $(S D)$} \\
\hline Months & Glass & PET & HDPE & PLA \\
\hline 0 & $0.1(0.01)$ & $0.1(0.01)$ & $0.1(0.01)^{\mathrm{a}^{*}}$ & $0.1(0.01)$ \\
3 & $0.10(0.01)$ & $0.11(0.01)$ & $0.10(0.01)^{* *}$ & $0.10(0.01)$ \\
5 & $0.10(0.01)$ & $0.11(0.31)$ & $0.12(0.01)^{* * *}$ & $0.12(0.02)$ \\
7 & $0.11(0.10)^{\mathrm{a}}$ & $0.12(0.01)$ & $0.15(0.01)^{\mathrm{a}, * * *}$ & $0.13(0.01)$ \\
9 & $0.12(0.01)^{\mathrm{b}}$ & $0.13(0.01)^{\mathrm{c}}$ & $0.23(0.25)^{\mathrm{b}, \mathrm{c}, \mathrm{d},,^{* * *}, * * *}$ & $0.12(0.01)^{\mathrm{d}}$ \\
\hline
\end{tabular}

${ }^{\mathrm{a}, \mathrm{b}, \mathrm{c}, \mathrm{d}} \mathrm{W}$ ithin each line, significant differences between materials at each time point $(P<0.05) .{ }^{\star}$ Within columns, significant differences between different time points for each material considered separately. SD = standard deviation.

Table 2. Results of mixed models ANOVA of the 4 investigated chemical parameters, acidity, PV, and extinction coefficients.

\begin{tabular}{|c|c|c|c|c|c|}
\hline & Type III Sum of Squares & df & Mean Square & $\mathbf{F}$ & $P$ \\
\hline \multicolumn{6}{|l|}{ Acidity } \\
\hline Storage Time & 0.015 & 3 & 0.005 & 27.342 & $<0.05$ \\
\hline Type of Packaging & 0.010 & 3 & 0.003 & 19.103 & $<0.05$ \\
\hline Storage Time ${ }^{\star}$ Packaging Type & 0.015 & 9 & 0.002 & 8.924 & $<0.05$ \\
\hline \multicolumn{6}{|l|}{ Peroxide Value } \\
\hline Storage Time & 3313.033 & 3 & 1104.344 & 1274.421 & $<0.05$ \\
\hline Type of Packaging & 154.267 & 3 & 51.422 & 59.342 & $<0.05$ \\
\hline Storage Time ${ }^{\star}$ Packaging Type & 96.272 & 9 & 10.697 & 12.344 & $<0.05$ \\
\hline \multicolumn{6}{|l|}{$\mathrm{K}_{232}$} \\
\hline Storage Time & 31.409 & 3 & 10.470 & 74.285 & $<0.05$ \\
\hline Type of Packaging & 1.286 & 3 & 0.429 & 3.041 & $<0.05$ \\
\hline Storage Time ${ }^{\star}$ Packaging Type & 3.814 & 9 & 0.424 & 3.007 & $<0.05$ \\
\hline \multicolumn{6}{|l|}{$\mathrm{K}_{270}$} \\
\hline Storage Time & 0.358 & 3 & 0.119 & 170.481 & $<0.05$ \\
\hline Type of Packaging & 0.004 & 3 & 0.001 & 1.832 & 0.161 \\
\hline Storage Time ${ }^{\star}$ Packaging Type & 0.034 & 9 & 0.004 & 5.368 & $<0.05$ \\
\hline
\end{tabular}


Table 3. Descriptive statistics with means and standard deviations of the PVs according packaging material and storage time.

\begin{tabular}{|c|c|c|c|c|}
\hline \multicolumn{5}{|c|}{ Peroxide Value (meq $\mathrm{O}_{2} / \mathrm{kg}$ ) Mean $(S D)$} \\
\hline Months & Glass & PET & HDPE & PLA \\
\hline 0 & $7.63(0.47)^{*}$ & $7.63(0.47)^{\bullet, \bullet \bullet}$ & $7.63(0.47)^{\#, \# \#}$ & $7.63(0.47)^{\star, \bullet \bullet}$ \\
\hline 3 & $8.17(0.29)^{\mathrm{a}, \mathrm{b}^{* *}}$ & $11.66(0.57)^{b \bullet \bullet}$ & $14.12(0.69)^{\mathrm{a}, \mathrm{b} \# \#}$ & $11.47(0.45)^{\mathrm{a}^{\star \star}}$ \\
\hline 5 & $12.63(1.47)^{* * * *}$ & $12.86(1.06)^{\bullet}$ & $13.94(1.22)^{\#}$ & $12.87(1.95)^{\star}$ \\
\hline 7 & $15.67(0.55)^{c^{* * * *}}$ & $15.27(0.55)^{\mathrm{d}, e \bullet, \bullet \bullet}$ & 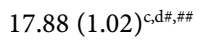 & $17.32(0.52)^{e^{e,, \bullet}}$ \\
\hline 9 & $29.16(0.76)^{f^{f, * *}}$ & $29.23(0.68)^{g^{\bullet}, \bullet \bullet}$ & 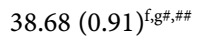 & $32.33(0.58)^{\mathrm{f}, \mathrm{g} \bullet, \bullet \bullet}$ \\
\hline
\end{tabular}

a,b,c,d,e,f,gWithin each line, significant differences between materials at each time point $(P<0.05)$. $*^{\bullet}, \#$, Within columns, significant differences between different time points for each material considered separately. ${ }^{*}$, Significant differences between different time points for Glass. ${ }^{\bullet}$, Significant difference between different time points for PET. *, Significant difference between different time points for HDPE. ", Significant difference between different time points for PLA. SD = standard deviation.

Table 4. Descriptive statistics with means and standard deviations of $\mathrm{K}_{232}$ according to the type of packaging material and storage time.

\begin{tabular}{|c|c|c|c|c|}
\hline \multicolumn{5}{|c|}{$\mathrm{K}_{232} \operatorname{Mean}(S D)$} \\
\hline Months & Glass & PET & HDPE & PLA \\
\hline 0 & $1.74(0.05)^{*}$ & $1.74(0.05)^{\bullet}$ & $1.74(0.05)^{\#}$ & $1.74(0.05)^{\bullet}$ \\
\hline 3 & $1.90(0.01)^{\mathrm{a}, \mathrm{b} * *}$ & $2.05(0.01)^{\mathrm{a}, \mathrm{b} b \bullet \bullet}$ & $2.31(0.01)^{\mathrm{b} \#}$ & $2.30(0.05)^{\mathrm{a}^{\star \star \bullet}}$ \\
\hline 5 & $2.67(0.03)$ & $2.45(0.14)^{\bullet}$ & $2.90(0.12)^{\#}$ & $2.74(0.70)^{\star}$ \\
\hline 7 & $3.62(0.02)^{c, d^{*}, * *}$ & $3.21(0.04)^{c^{\bullet}, \bullet \bullet}$ & $3.48(0.08)^{\mathrm{c}, \mathrm{d} \#}$ & $3.08(0.01)^{\mathrm{d} \bullet}$ \\
\hline 9 & $3.98(1.21)^{* * * *}$ & $3.94(0.43)^{\bullet, \bullet \bullet}$ & $4.03(0.16)^{\#}$ & $3.89(0.18)^{*, \cdot 4}$ \\
\hline
\end{tabular}

a,b,c,d,Within each line, significant differences between materials at each time point $(P<0.05) . * \bullet, * \bullet$ Within columns, significant differences between different time points for each material considered separately. *, Significant differences between different time points for Glass. ${ }^{\bullet}$, Significant difference between different time points for PET. *, Significant difference between different time points for HDPE. ", Significant difference between different time points for PLA. SD = standard deviation.

Table 5. Descriptive statistics with means and standard deviations of $K_{270}$ according to the type of packaging material and storage time.

\begin{tabular}{|c|c|c|c|c|}
\hline \multicolumn{5}{|c|}{$\mathrm{K}_{270}$ Mean $(S D)$} \\
\hline Months & Glass & PET & HDPE & PLA \\
\hline 0 & $0.22(0.01)^{* * * * * *}$ & $0.22(0.01)^{\bullet \bullet \bullet \bullet \bullet ~}$ & 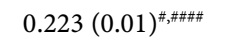 & $0.22(0.01)^{\star}$ \\
\hline 3 & $0.21(0.01)^{\mathrm{a}^{* * * * * * *}}$ & $0.21(0.01)^{\mathrm{b}, \boldsymbol{c} \bullet \bullet, \bullet \bullet \bullet \bullet ~}$ & 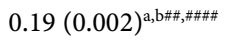 & $0.25(0.01)^{\mathrm{a}, \mathrm{c}+\mathrm{t}}$ \\
\hline 5 & $0.22(0.004)^{* * * * * * * *}$ & $0.24(0.03)^{\bullet \bullet \bullet, \bullet \bullet \bullet \bullet ~}$ & 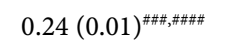 & $0.25(0.02)^{\bullet \bullet \bullet}$ \\
\hline 7 & $0.41(0.01)^{\mathrm{d}^{\mathrm{d} * * *}}$ & $0.40(0.04)^{\mathrm{e}^{\bullet \bullet \bullet \bullet}}$ & 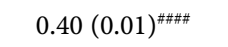 & $0.25(0.03)^{\mathrm{d}, e,, \bullet, \cdot \bullet \bullet}$ \\
\hline 9 & $0.41(0.01)^{*, * *, * * *}$ & $0.40(0.04)^{\bullet, \bullet \bullet, \bullet \bullet ~}$ & 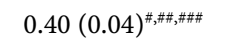 & $0.33(0.01)^{\varphi, *+, \bullet \varphi}$ \\
\hline
\end{tabular}

a,b,c,d,e Within each line, significant differences between materials at each time point $(P<0.05) . * \bullet, * \bullet$ Within columns, significant differences between different time points for each material considered separately. ${ }^{*}$, Significant differences between different time points for Glass. ${ }^{\bullet}$, Significant difference between different time points for PET. *, Significant difference between different time points for HDPE. ", Significant difference between different time points for PLA. SD = standard deviation. 
Table 6. Descriptive statistics with means and standard deviations of the fatty acid profile according to packaging material and storage time.

\begin{tabular}{|c|c|c|c|c|}
\hline & \multicolumn{4}{|c|}{$\begin{array}{l}\text { Fatty Acid Composition (\%) } \\
\text { Mean }(S D)\end{array}$} \\
\hline & Oleic Acid & Palmitic Acid & Linoleic Acid & Stearic Acid \\
\hline \multicolumn{5}{|c|}{ GLASS } \\
\hline 0 & $73.0(0.6)^{*}$ & $12.7(0.5)^{*}$ & $8.0(0.16)^{*, * *, * * *}$ & $5.5(0.1)^{*}$ \\
\hline 3 & $68.2(0.4)^{\mathrm{a} \star}$ & $12.6(0.8)^{\mathrm{a}, \mathrm{b}^{* *}}$ & $14.2(0.1)^{\mathrm{a}^{* *}}$ & $5.8(0.5)^{\mathrm{a}, \mathrm{b}^{* *}}$ \\
\hline 5 & $64.7(0.6)^{\mathrm{b} *}$ & $15.5(1.4)^{c^{* * *}}$ & $14.0(0.6)^{\mathrm{d}^{* * *}}$ & $6.8(0.7)^{\mathrm{e}^{\mathrm{e}, * * *}}$ \\
\hline 7 & $55.4(0.7)^{c *}$ & $20.6(0.6)^{\mathrm{e}^{*}, * * * * * *}$ & $13.9(0.2)^{*}$ & $10.6(0.8)^{\mathrm{h}, \mathrm{i}^{*}, * * * * *}$ \\
\hline 9 & $36.1(0.5)^{\mathrm{ex}}$ & $23.2(2.5)^{\mathrm{g}^{\mathrm{g}, \mathrm{h}^{*}, * *, * * *}}$ & $16.3(1.4)^{g^{*, * * * * * *}}$ & $13.7(1.9)^{\mathrm{j}, \mathrm{k}^{* * * * * * * *}}$ \\
\hline \multicolumn{5}{|c|}{ PET } \\
\hline 0 & $73.0(0.6)^{\bullet, \bullet, \bullet \bullet \bullet}$ & $12.7(0.40)^{\bullet}$ & $8.0(0.16)^{\bullet, \cdots \bullet, \cdots \bullet}$ & $5.5(0.1)^{\bullet, \bullet, \bullet \bullet \bullet ~}$ \\
\hline 3 & $49.1(0.6)^{\mathrm{a} \bullet}$ & $26.1(0.3)^{\mathrm{a}^{\bullet}}$ & $8.8(0.9)^{\mathrm{a}, \mathrm{b} \bullet \bullet, \bullet \bullet \bullet, \bullet \bullet \bullet \bullet ~}$ & $12.7(0.4)^{\mathrm{a}, \mathrm{d} \bullet \bullet}$ \\
\hline 5 & $60.0(0.2)^{\mathrm{b} \bullet, \bullet \bullet, \bullet \bullet}$ & $15.3(0.7)^{\mathrm{d} \bullet}$ & $14.1(0.5)^{\mathrm{e} \bullet \bullet \bullet}$ & $4.9(0.8)^{g \bullet \bullet, \bullet \bullet \bullet ~}$ \\
\hline 7 & $49.1(1.1)^{c, \mathrm{~d} \bullet, \cdots \bullet}$ & $24.0(0.2)^{\mathrm{e}, \mathrm{f} \bullet}$ & $14.3(0.6)^{\mathrm{f} \bullet, \bullet \bullet, \cdots \bullet \bullet}$ & $12.7(0.4)^{\mathrm{h}, \mathrm{\bullet} \bullet \bullet}$ \\
\hline 9 & $50.2(1.4)^{\mathrm{e} \bullet, \bullet \bullet, \bullet \bullet}$ & $21.5(1.4)^{\mathrm{g} \bullet}$ & $13.0(0.1)^{\bullet, \bullet \bullet}$ & $19.0(0.8)^{j \bullet \bullet \bullet \bullet, \bullet \bullet \bullet ~}$ \\
\hline \multicolumn{5}{|c|}{ HDPE } \\
\hline 0 & $73.0(0.6)^{\#, \#,}$ & $12.7(0.40)^{\#, \# \#}$ & 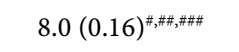 & $5.5(0.1)^{\#, \# \#}$ \\
\hline 3 & $51.4(1.0)^{\mathrm{a} \# \#,}$ & $24.6(0.7)^{\mathrm{bH},}$ & 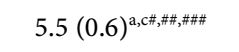 & $12.3(0.2)^{\mathrm{b}, c \# \#, \# \# \#}$ \\
\hline 5 & $54.0(0.9)^{\mathrm{bH},}$ & $22.1(0.5)^{\mathrm{c}, \mathrm{d} \#}$ & $11.2(0.4)^{\mathrm{d} \text {,e\#\# }}$ & $3.8(0.8)^{e^{e, f \# \# \#}}$ \\
\hline 7 & $45.5(0.8)^{c, d \#, \# \#}$ & $23.3(1.1)^{\# \#}$ & $12.5(0.6)^{\mathrm{fH},}$ & 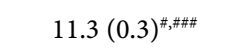 \\
\hline 9 & 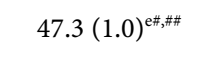 & 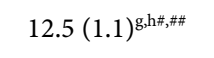 & $12.1(1.2)^{g^{\# \# \#}}$ & 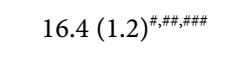 \\
\hline \multicolumn{5}{|c|}{ PLA } \\
\hline 0 & $73.0(0.6)^{\star}$ & $12.7(0.40)^{+, \bullet,+\bullet \bullet}$ & $8.0(0.16)^{\bullet+\bullet,+,+\bullet,+\bullet \bullet \bullet}$ & $5.5(0.1)^{\bullet,+\bullet \bullet,+\bullet+\bullet}$ \\
\hline 3 & $59.7(0.9)^{a^{\star}}$ & $18.1(0.7)^{\mathrm{a}, \mathrm{b}+\bullet \bullet}$ & $14.1(0.2)^{\mathrm{b}, \mathrm{c}+\bullet \bullet}$ & $6.5(0.6)^{c, d \oplus \bullet,+\varphi, \cdot, * \bullet}$ \\
\hline 5 & $48.0(0.4)^{\mathrm{b} \bullet}$ & $26.4(0.7)^{\mathrm{c}, \mathrm{d} \varphi, \bullet, \cdot, \bullet}$ & $12.6(0.6)^{\bullet}$ & $10.6(0.6)^{e, f, g, \bullet, \bullet,, * \bullet}$ \\
\hline 7 & $54.1(1.4)^{\mathrm{d} \bullet}$ & $20.8(1.4)^{\mathrm{f} \bullet \bullet}$ & $13.6(0.5)^{* *}$ & $11.0(0.4)^{\mathrm{i} \bullet \bullet+\bullet}$ \\
\hline 9 & $43.0(1.8)^{\mathrm{e}^{\star}}$ & $17.3(1.8)^{\mathrm{i} \bullet, \oplus}$ & $14.1(1.8)^{* * * \bullet}$ & $18.1(0.8)^{\mathrm{j}, \mathrm{k}, \bullet \bullet \bullet,+\bullet,+\bullet \bullet \bullet}$ \\
\hline
\end{tabular}

a,b,c,d,e,f,g,h,i,j,k Within each line, significant differences between materials at each time point $(P<0.05)$. ${ }^{\bullet} \bullet$, \#, Within columns, significant differences between different time points for each material considered separately. ${ }^{*}$, Significant differences between different time points for Glass. ${ }^{\bullet}$, Significant difference between different time points for PET. *, Significant difference between different time points for HDPE. ", Significant difference between different time points for PLA. SD = standard deviation.

Table 7. Results of mixed models ANOVA.

\begin{tabular}{cccccc}
\hline & Type III Sum of Squares & df & Mean Square & F & $P$ \\
\hline Oleic Acid & & & & & \\
Storage Time & 0.015 & 3 & 0.005 & 27.342 & $<0.05$ \\
Type of Packaging & 0.010 & 3 & 0.003 & 19.103 & $<0.05$ \\
Storage Time*Packaging Type & 0.015 & 9 & 0.002 & 8.924 & $<0.05$ \\
\hline
\end{tabular}




\section{Continued}

\begin{tabular}{cccccc}
\hline $\begin{array}{c}\text { Palmitic Acid } \\
\text { Storage Time }\end{array}$ & 3313.033 & 3 & 1104.344 & 1274.421 & $<0.05$ \\
Type of Packaging & 154.267 & 3 & 51.422 & 59.342 & $<0.05$ \\
$\begin{array}{c}\text { Storage Time^Packaging Type } \\
\text { Linoleic Acid }\end{array}$ & 96.272 & 9 & 10.697 & 12.344 & $<0.05$ \\
$\begin{array}{c}\text { Storage Time } \\
\text { Type of Packaging }\end{array}$ & 31.409 & 3 & 10.470 & 74.285 & $<0.05$ \\
$\begin{array}{c}* \\
\text { Storage Time Packaging Type }\end{array}$ & 1.286 & 3 & 0.429 & 3.041 & $<0.05$ \\
Stearic Acid & 3.814 & 9 & 0.424 & 3.007 & $<0.05$ \\
Storage Time & & & & & \\
Type of Packaging & 0.358 & 3 & 0.119 & 170.481 & $<0.05$ \\
Storage Time ${ }^{\star}$ Packaging Type & 0.004 & 3 & 0.001 & 1.832 & 0.161 \\
\hline
\end{tabular}

The present study aimed at comparing the impact of 3 types of plastic packaging (PET, HDPE, and PLA) on Lebanese EVOO under real-time storage conditions up to 9 months. The results showed that increasing storage time negatively affected the quality parameters of EVOO in contact with glass and plastic materials leading to increased acidity, PV, and extinction coefficients $\mathrm{K}_{232}$ and $\mathrm{K}_{270}$. Interaction phenomena at the interface emerged at 3 to 5 months and increased significantly at later evaluation intervals for the 3 plastic materials.

The present experimental design combines the total immersion protocol with real-time storage conditions in Lebanese households during a storage period of 9 months. The total immersion protocol was adapted from the norm NF-EN-1186-2 of materials and articles in contact with foodstuffs [18], and has been applied in several investigations with similar objectives [10] [11] [13] [16]. While accelerated conditions under temperatures ranging between $25^{\circ} \mathrm{C}$ and $60^{\circ} \mathrm{C}$ were adopted in several studies for short time periods (from 10 to 60 days) to simulate long-term storage at ambient temperature [11] [16] [21], other investigations used real-time storage temperatures between $24^{\circ} \mathrm{C}$ and $37^{\circ} \mathrm{C}$ for longer time intervals [13]. Although accelerated storage conditions are useful for determining EVOO shelf life within a short period of time, the main drawback of these methods is that the autoxidation process takes place under drastic conditions and leads to either under prediction or over prediction of the actual shelf-life of EVOO [6] [8] [21]. In fact, several investigations demonstrated a lack of correlation between EVOO stability measured by means of accelerated tests and under normal storage conditions [6] [21] [22]. In addition, the oxidation mechanism is significantly different at high temperatures and results in the formation of oxidation products, in particular volatile compounds, which are not produced in significant amounts under normal storage conditions [21]. It is likely that real-time storage conditions reflect actual changes in EVOO matrix over time as the degradation of EVOO proceeds slowly under normal storage 
conditions. In the present study, storage parameters paralleled the actual climatic fluctuations from mid-November to mid-August in Lebanon with temperatures ranging between $14^{\circ} \mathrm{C}$ and $32^{\circ} \mathrm{C}$. No attempt was made to stabilize the storage conditions in the storage compartment. Although some authors recommend maintaining consistent storage parameters under non-accelerated conditions [8] this requires alternating cooling and heating and involves a substantial effort which is not a mentality trait of the common Mediterranean populations.

The GC-MS extraction method to quantify interaction of EVOO with plastic packaging materials and determine the fatty acid profile was adopted according to the norm NF-EN-1186-2. The GC is a well established method and has been used widely for the same purposes [10] [11] [12] [13] [14]. When coupled with MS as the detector, it allows to identify and quantify specific components in a sample [23].

Increasing storage time had a significant negative impact on the quality parameters of the EVOO investigated in the present study whether the oil was in contact with glass or plastic material. These results are in agreement with the findings of several studies that investigated glass- and plastic-stored olive oil under accelerated [10] [24] and non-accelerated storage conditions [1] [5] [7] [12] [14] [25] [26] [27]. While most authors concord that quality parameters tend to deteriorate with time, there is no consensus as to the timing and degree of deleterious changes that occur. These discrepancies can be attributed to differences in baseline characteristics of the olive oil, filtration and refinement, experimental design and storage conditions, and assessment techniques.

\section{Changes in physico-chemical characteristics of EVOO}

In this study, the acidity of EVOO stored in clear glass without light exposure barely increased at the end of the 9-month storage period and remained below the established values for EVOO, however the PVs exceeded the upper standard limit of EVOO (20 meq $\mathrm{O}_{2} / \mathrm{kg}$ oil) (Table 1 and Table 3 ). Peroxides are the main initial products resulting from lipid autoxidation during storage and serve as indicators of the degree of oxidative rancidity and quality change [12]. Although there is synergy between lipolysis (responsible for the increase in acidity) and lipid oxidation (responsible for the increase in PV), the latter can be accelerated by increased temperature, presence of water, and oxidative enzymes that are increased in case of fly spoilage [2]. The drastic increase in PV emerged after 7 months (Table 3) of storage, coinciding with summer heat during the months of July and August. In addition, traditionally produced Lebanese EVOOs are characterized by the lack of filtration and the inclusion of fly-damaged olives in the pressed olive batches. This can result in greater amounts of vegetation water within the oil and fungal/bacterial contamination resulting in increased enzymatic oxidizing activity and substantial progressive increase in PV beyond the maximum limit. Another potential reason that could account for the marked increase in acidity and PV is the migration of antacids such as zinc and calcium stearate or inorganic pigments commonly used in plastic packaging formula- 
tions [9] [10]. This migration is likely to have reached greater values with the increase of temperature and the extended storage time in July-August [13] [28]. $\mathrm{PV}$ and $\mathrm{K}_{232}$ reflect the primary lipid oxidation while $\mathrm{K}_{270}$ is a secondary oxidation product [5]. In glass, the marked increase in $K_{232}$ and $K_{270}$ paralleled PVs and was similarly evident during the hottest summer months with values higher than the legal limits. This finding corroborates the results of previous investigations where both extinction coefficients tended to be negatively affected by increasing temperatures [5] [24].

When plastic materials are considered, both time and packaging type showed a significant impact on the acidity and PVs of the investigated EVOO $(P<0.001)$ (Table 2). Acidity significantly increased with increasing storage time only in the HDPE group but remained within the EVOO specifications up to the end of the experimental period. At 7 months, acidity was significantly higher than that observed at baseline $(P=0.013)$, and 3 months $(P=0.021)$. At 9 months, EVOO acidity in the HDPE group was significantly higher than PLA and PET $(P<$ 0.001) (Table 2). The PVs exceeded the upper standard limit of EVOO at 9 months for all 3 plastic materials but were significantly greater for HDPE than for PLA and PET materials. The significant statistical interactions between time and packaging material for both acidity and PV parameters in the mixed model ANOVA indicate that the time-dependent chemical interaction between plastics and olive oil is different among the 3 packaging materials $(P<0.001)$ (Table 2$)$. HDPE seems in this regard more susceptive to increasing storage time than the other 2 plastic materials. The increase of $\mathrm{K}_{232}$ was significantly higher for HDPE than for PLA and PET at 7 months $(P<0.001)$ (Table 4$)$. This pattern was also evident at 9 months but the differences did not reach statistical significance. For $\mathrm{K}_{270}$ the differences between plastic materials were only significant at the 7-month storage period (Table 5). This lack of clear-cut differences in the extinction coefficients among the 3 plastic materials are confirmed by the non significant impact of packaging materials on $\mathrm{K}_{270}$ in the mixed model ANOVA $(P=$ 0.161) (Table 2). While the changes in EVOO quality parameters followed a logical development in the glass containers due to naturally occurring auto-oxidation, the evolution trend in the plastic packaging materials was more complex with no distinct linear relationship, rendering more difficult an objective selection of the best plastic material for EVOO storage. Under the study conditions, PLA and PET materials seem to behave fairly similarly relative to acidity up to 9 months and PVs up to 5 months, while HDPE demonstrated the highest oxidative and lipolytic deterioration throughout the 9-month storage period. The low oxidative stability of HDPE in contact with EVOO has been confirmed by the two other investigations comparing the impact of HDPE and PET on EVOO under dark storage conditions [5] [7].

\section{Changes in fatty acids composition}

In the present study, mixed models ANOVA indicated that storage time and packaging material had a significant impact $(P<0.001)$ on the fatty acid profile 
(Table 7). Oleic acid was the most abundant fatty acid at baseline and at all successive evaluation periods ranging between $36.1 \%$ and $73 \%$ (Table 6). Oleic acid, decreased with increasing storage time in all packaging materials, while saturated fatty acids (palmitic and stearic acids) tended to increase (Table 6), similarly to the findings of Dabbou et al. (2011) and El Haouhay et al. (2018) [12] [14]. The autoxidation of olive oil-represented partly by oleic acid decrease-in contact with glass tended to proceed gradually and slowly during storage up to the 7 th month then worsened markedly after that, in concomitance with the hottest summer months. Oleic acid in contact with the plastic materials decreased more drastically than in glass after 3 months then slowed down during the following months. While oleic acid decreased significantly with increasing storage time for all packaging glass and plastic materials (Table 6), the percentage contents in palmitic, linoleic, and stearic acids showed some differences among the plastic materials, without however a specific trend. The saturated fatty acids, palmitic acid and stearic increased significantly after 7 months of storage in glass and at 3 months and beyond for the plastic materials. This could be explained by the impact of plastics which may initially favor lipolytic activity, but counteract it in the later storage periods due to the release of migrants with antioxidant activity integrated into the composition of PLA [10], HDPE, and PET [29].

The decrease in oleic acid and greater contents in linoleic, palmitic and stearic acids during the later periods of storage are in agreement with the conclusions of several previous investigations testing olive oil in contact with PET [12] [14], but in disagreement with other studies [1] [11] that found no significant variation of fatty acid composition with olive oil contacting PET. Data relative to the impact of HDPE and PLA on the fatty acid profile of olive oil could not be found in the literature.

\section{Migration and sorption}

Migration and sorption phenomena are routinely evaluated to ensure that the amount of migrating components from plastics to foodstuff meet compliance standards set by regulatory agencies. Both phenomena are markedly influenced by several parameters such as packaging material type [10] [13], temperature [11] [13], contact time and the fat content of the food products [28]. In the present study, oil sorption and overall migration increased with extending storage time for all three packaging materials. Differences in sorption and migration between the 3 plastic packaging materials became significant at 3 months with PET showing significantly higher sorption than PLA (Table 8). Migration followed a similar pattern of increase as sorption for all 3 plastic materials (Table 8) except for PET which demonstrated comparable sorption values between 7 and 9 months. Overall, PET was mostly affected at all evaluation intervals, followed by HDPE and PLA. The amount of sorbed oil in PET at the 9th month reached $8.57 \pm 0.54 \mathrm{mg} / \mathrm{dm}^{2}$, which is nearly 2 times that found with $\operatorname{HDPE}\left(4.74 \pm 0.54 \mathrm{mg} / \mathrm{dm}^{2}\right)$ and PLA $\left(3.79 \pm 0.34 \mathrm{mg} / \mathrm{dm}^{2}\right)$.

Similar conclusions have been reported in investigations comparing vegetable 
oil [16] and EVOO [12] in contact with PET versus PLA. To the authors' knowledge, there is no published information related to migration/sorption when olive oil is in contact with PET versus HDPE or with HDPE versus PLA. It should be noted that although sorption/migration for all 3 plastic materials were within the specified limit of the Commission Regulation (EU) No 10/2011 of $\mathrm{mg} / \mathrm{dm}^{2}[30]$.

Overall, the storage time and the type of packaging had a significant impact on sorption and migration with $P<0.05$ (Table 9). The interaction between storage time and packaging type was also significant $(P<0.001)$ indicating a dependent effect of time and material on sorption (Table 9 ).

Several material-related intrinsic properties may be responsible for the sorption behaviour of polymers: density and free volume ("holes" present within the amorphous region), polarity of the functional groups, hydrophilicity, glass transition temperature, and crystallinity [31]. In general, hydrophilic polymers of high crystallinity, high glass transition temperature, and high polarity sorb generally less oil than hydrophobic and rubbery polyolefins which are mainly amorphous [10] [13] [16] [31]. There are also marked differences in the physicochemical characteristics of materials belonging to the same polymer family. Although both PET and PLA are semi-crystalline polyesters, they differ greatly in structure and in behavior [32]. The total crystallinity of PET produced by solid state polymerization can be as high as 55\% [33]. PLA's crystallinity is greatly dependent on the percentage of ${ }_{\mathrm{L}}$-Lactide. PLA deriving from greater than $93 \%$ L-Lactic acid can be semi-crystalline whereas PLA from between 50\% and 93\% L-Lactic acid is strictly amorphous [17]. Great variations in PLA's crystallinity have been reported between manufacturers with ranges between $25 \%$ and $40 \%$ [17], and between $45 \%$ and $60 \%$ [34]. PLA is slightly more hydrophobic than PET [17] with a glass transition temperature (ranging between $55^{\circ} \mathrm{C}$ and $65^{\circ} \mathrm{C}$ ) lower than that of PET $\left(77^{\circ} \mathrm{C}\right)$ [32]. The higher sorption demonstrated by PET can be attributed to the fact that PET has a lower crystallinity than the other materials.

Table 8. Descriptive statistics with means and standard deviations of sorption and migration according to packaging material and storage time.

\begin{tabular}{|c|c|c|c|c|c|c|}
\hline \multirow[b]{2}{*}{ Months } & \multicolumn{3}{|c|}{$\begin{array}{c}\text { Sorption }\left(\mathrm{mg} / \mathrm{dm}^{2}\right) \\
\text { Mean }(S D)\end{array}$} & \multicolumn{3}{|c|}{$\begin{array}{c}\text { Global Migration }\left(\mathrm{mg} / \mathrm{dm}^{2}\right) \\
\text { Mean }(S D)\end{array}$} \\
\hline & PET & HDPE & PLA & PET & HDPE & PLA \\
\hline 3 & $1.37(0.34)^{\mathrm{a}^{* * * *}}$ & $1.23(0.54)^{+, \bullet, * \bullet \bullet}$ & $0.254(0.09)^{\mathrm{a} \bullet, \bullet \bullet, \bullet \bullet}$ & $1.26(0.31)^{\mathrm{a}^{*, * *}}$ & $0.94(0.41)^{+, *,+\bullet \bullet}$ & $0.16(0.06)^{a},, \bullet \bullet, \bullet \bullet$ \\
\hline 5 & $5.31(0.54)^{\mathrm{b}, \mathrm{c}^{* *}}$ & $3.65(0.54)^{\mathrm{b} \bullet \bullet}$ & $2.89(0.54)^{\mathrm{c} \bullet \bullet}$ & $4.75(0.72)^{b, c^{*}, * *}$ & $2.85(0.65)^{\mathrm{b} \bullet \bullet}$ & $2.79(0.54)^{\mathrm{c} \bullet \bullet}$ \\
\hline 7 & $6.13(0.31)^{\mathrm{d}^{*}}$ & $4.38(0.24)^{\mathrm{d} \bullet \bullet \bullet}$ & $3.24(0.20)^{\mathrm{d} \bullet \bullet \bullet}$ & $6.56(0.13)^{\mathrm{d}, \mathrm{e}^{* *}}$ & $3.57(0.21)^{\mathrm{d} \bullet \bullet \bullet}$ & $3.23(0.19)^{\mathrm{e} \bullet \bullet \bullet}$ \\
\hline 9 & $8.57(0.54)^{e, f^{*}, * *}$ & $4.74(0.54)^{\mathrm{e}^{\bullet}}$ & $3.79(0.34)^{\mathrm{f}^{\bullet}}$ & $6.58(0.42)^{\mathrm{f}^{*}}$ & $4.73(0.53)^{f \mathbf{f}, \bullet \bullet}$ & $3.32(0.29)^{\mathrm{f}^{\bullet}}$ \\
\hline
\end{tabular}

a,b,c,d,e,fWithin each line, significant differences between materials at each time point $(P<0.05) .{ }^{*}, \bullet, *$ Within columns, significant differences between different time points for each material considered separately. ${ }^{\star}$, Significant differences between different time points for Glass. ${ }^{\bullet}$, Significant difference between different time points for PET. *, Significant difference between different time points for HDPE. ${ }^{\star}$, Significant difference between different time points for PLA. $\mathrm{SD}=$ standard deviation. 
Table 9. Results of mixed models ANOVA.

\begin{tabular}{|c|c|c|c|c|c|}
\hline & Type III Sum of Squares & df & Mean Square & F & $P$ \\
\hline \multicolumn{6}{|l|}{ Sorption } \\
\hline Storage Time & 111.295 & 3 & 37.098 & 206.683 & $<0.05$ \\
\hline Type of Packaging & 48.652 & 2 & 24.326 & 135.526 & $<0.05$ \\
\hline Storage Time ${ }^{\star}$ Packaging Type & 13.883 & 6 & 2.314 & 12.891 & $<0.05$ \\
\hline \multicolumn{6}{|l|}{ Migration } \\
\hline Storage Time & 91.139 & 3 & 30.380 & 169.489 & $<0.05$ \\
\hline Type of Packaging & 37.516 & 2 & 18.758 & 104.651 & $<0.05$ \\
\hline Storage Time ${ }^{\star}$ Packaging Type & 8.129 & 6 & 1.355 & 7.559 & $<0.05$ \\
\hline
\end{tabular}

\section{Pearson correlation}

The significant positive correlations demonstrated between $\mathrm{PV}$ and \% acidity and between $\mathrm{PV}$ and $\mathrm{K}_{232}$ with glass $(\mathrm{r}=0.74 ; P=0.002 ; \mathrm{r}=0.79 ; P<0.001)$, PET $(\mathrm{r}=0.67 ; P=0.006 ; \mathrm{r}=0.90 ; P<0.001)$, HDPE $(\mathrm{r}=0.95 ; P<0.001 ; \mathrm{r}=0.86 ; P<$ $0.001)$ and PLA $(\mathrm{r}=0.57 ; P=0.027 ; \mathrm{r}=0.96 ; P<0.001)$ confirm the importance of $\mathrm{PV}$ as an in indicator of the oxidative process and therefore oil quality [5] [35]. $\mathrm{K}_{232}$ and $\mathrm{K}_{270}$ were also significantly and positively correlated for all 4 packaging materials (glass: $\mathrm{r}=0.86, P<0.001$; PET: $\mathrm{r}=0.88, P<0.001$; HDPE: $\mathrm{r}=$ $0.88, P<0.001$; PLA: $\mathrm{r}=0.96, P<0.001$ ) (Table 10 ) implying a direct relationship between primary and secondary oxidation products [5]. The relationship between PV and $\mathrm{K}_{270}$ has not been consistently reported. While Abbadi et al. (2014) found no significant correlation between PV and $K_{270}$ [5], other investigators demonstrated a significant positive correlation between the two parameters in agreement with the results of the present study [35]. Such discrepancies are difficult to interpret due to marked differences in the experimental designs and storage conditions.

Migration increased with increasing sorption as shown by the very high positive significant correlation between the 2 variables with $r$ values exceeding 0.94 for the 3 plastic packaging materials (Table 11). Regarding the significant positive association between migration and sorption, this finding corroborates with the results of other investigators [10] and was expected since olive oil sorbed into the polymer matrix is likely to induce a swelling of the polymer and therefore promote migration [10] [13].

Although PET is considered the plastic of choice when it comes to recycling [32], there is a current trend towards replacing the petroleum-derived polymers with more sustainable materials such as the bio-derived PLA. PLA has higher tensile strength and flexural modulus that HDPE and similar mechanical properties to PET [32]. The overall results of the present study suggest that PLA displays less alteration of the quality parameters during the storage period and was associated with less sorption/ migration than HDPE and PET. It may be therefore suggested that PLA could be an alternative option for EVOO storage for short time periods of 5 months or less under household storage conditions. 
Table 10. Pearson coefficients between quality parameters of the investigated olive oil.

\begin{tabular}{cccccccccccccccccc}
\hline & \multicolumn{4}{c}{$\%$ Acidity } & \multicolumn{4}{c}{ PV } & \multicolumn{4}{c}{$\mathrm{K}_{232}$} & \multicolumn{4}{c}{$\mathrm{K}_{270}$} \\
\cline { 2 - 6 } & Glass & PET & HDPE & PLA & Glass & PET & HDPE & PLA & Glass & PET & HDPE & PLA & Glass & PET & HDPE & PLA \\
\hline \% Acidity & - & - & - & - & $0.74^{* *}$ & $0.67^{* *}$ & $0.95^{* *}$ & $0.57^{*}$ & 0.49 & $0.58^{*}$ & $0.87^{* *}$ & $0.56^{*}$ & $0.55^{*}$ & 0.45 & $0.90^{* *}$ & $0.54^{*}$ \\
PV & $0.74^{* *}$ & $0.67^{* *}$ & $0.95^{* *}$ & $0.57^{*}$ & - & - & - & - & $0.79^{* *}$ & $0.90^{* *}$ & $0.86^{* *}$ & $0.96^{* *}$ & $0.67^{* *}$ & $0.69^{* *}$ & $0.81^{* *}$ & $0.97^{* *}$ \\
$\mathrm{~K}_{232}$ & 0.49 & $0.58^{*}$ & $0.87^{* *}$ & $0.56^{*}$ & $0.79^{* *}$ & $0.90^{* *}$ & $0.86^{* *}$ & $0.96^{* *}$ & - & - & - & - & $0.86^{* *}$ & $0.88^{* *}$ & $0.88^{* *}$ & $0.96^{* *}$ \\
$\mathrm{~K}_{270}$ & $0.55^{*}$ & 0.45 & $0.90^{* *}$ & $0.54^{*}$ & $0.67^{* *}$ & $0.68^{* *}$ & $0.81^{* *}$ & $0.97^{* *}$ & $0.86^{* *}$ & $0.88^{* *}$ & $0.88^{* *}$ & $0.96^{* *}$ & - & - & - & - \\
\hline
\end{tabular}

${ }^{*}$ Correlation is significant at the 0.01 level (2-tailed), ${ }^{*}$ Correlation is significant at the 0.05 level (2-tailed).

Table 11. Pearson coefficients between sorption and migration phenomena.

\begin{tabular}{ccccccc}
\hline & \multicolumn{3}{c}{ Sorption } & \multicolumn{3}{c}{ Migration } \\
\cline { 2 - 7 } & PET & HDPE & PLA & PET & HDPE & PLA \\
\hline Sorption & - & - & - & $0.94^{* *}$ & $0.97^{* *}$ & $0.99^{* *}$ \\
Migration & $0.94^{* *}$ & $0.97^{* *}$ & $0.99^{* *}$ & - & - & - \\
\hline
\end{tabular}

\section{Conclusions}

Based on the results of the present study, the following conclusions can be drawn:

1) Under real-time storage conditions in a Lebanese household, the quality parameters of Lebanese EVOO deteriorated when in contact with glass, PET, HDPE, and PLA polymers, especially between the 7th and 9th month of storage which coincide with warmest months of the year.

2) Glass remains a better container for EVOO than polymeric materials under ambient storage temperatures and for extended periods of time.

3) A significant interaction was demonstrated between storage material and time relative to the quality parameters, fatty acid composition, and interaction phenomena indicating the 3 polymers respond differently to increasing storage time.

4) Overall, oil in contact with PLA showed the least quality deterioration and interaction phenomena among the 3 plastic materials during the 9-month storage period.

Further studies are required to clarify the impact of PLA on the sensory/organoleptic characteristics of olive oil and the nature of the migrants resulting from the interaction with the polymer.

\section{Acknowledgements}

We are grateful for Prof. Zeina Majzoub's outstanding help that she has provided us with in the statistical analysis section.

\section{Conflicts of Interest}

The authors declare no conflicts of interest regarding the publication of this paper. 


\section{References}

[1] Méndez, A.I. and Falque, E. (2007) Effect of Storage Time and Container Type on the Quality of Extra Virgin Olive Oil. Food Control, 18, 521-529.

https://doi.org/10.1016/j.foodcont.2005.12.012

[2] Mariotti, M. (2014) Virgin Olive Oil: Definition and Standards. In: Peri, C., Ed., The Extra-Virgin Olive Oil Handbook, Wiley-Blackwell, Hoboken, 11-19. https://doi.org/10.1002/9781118460412.ch2

[3] IOC (2007) COI/T.20/Doc. $n^{\circ} 15 /$ Rev 2. International Olive Oil Council, Madrid. https://www.internationaloliveoil.org/wp-content/uploads/2019/11/INTERNATIO NAL-OLIVE-OIL-PRODUCTION-COSTS-STUDY-.pdf

[4] Piscopo, A. and Poiana, M. (2012) Packaging and Storage of Olive Oil. In: Muzzalupo, I., Ed., Olive Germeplasm-The Olive Cultivation, Table Olive and Olive Oil Industry in Italy, InTechOpen, London, 201-222. https://doi.org/10.5772/51827

[5] Abbadi, J., Afaneh, I., Ayyad, Z., Al-Rimawi, F., Sultan, W. and Kanaan, K. (2014) Evaluation of the Effect of Packaging Materials and Storage Temperatures on Quality Degradation of EVOO from Olives Grown in Palestine. American Journal of Food Science and Technology, 2, 162-174. https://doi.org/10.12691/ajfst-2-5-5

[6] Velasco, J. and Dobarganes, C. (2002) Oxidative Stability of Virgin Olive Oil. European Journal of Lipid Science and Technology, 104, 661-676.

https://doi.org/10.1002/1438-9312(200210)104:9/10<661::AID-EJLT661>3.0.CO;2$\underline{\mathrm{D}}$

[7] Afaneh, I., Abbadi, J., Ayyad, Z., Sultan, W. and Kanan, K. (2013) Evaluation of Selected Quality Indicators of Extra Virgin Olive Oil Bottled in Different Packaging Materials upon Storage under Different Lighting Conditions. Journal of Food Science and Engineering, 3, 267-283. https://doi.org/10.12691/ajfst-2-5-5

[8] Li, X. and Wang, C.S. (2018) Shelf Life of Extra Virgin Olive Oil and Its Prediction Models. Journal of Food Quality, 2018, Article ID: 1639260.

https://doi.org/10.1155/2018/1639260

[9] Hahladakis, J.N., Velis, C.A., Weber, R., Iacovidou, E. and Purnell, P. (2018) An Overview of Chemical Additives Present in Plastics: Migration, Release, Fate and Environmental Impact during Their Use, Disposal and Recycling. Journal of Hazardous Materials, 344, 179-199. https://doi.org/10.1016/j.jhazmat.2017.10.014

[10] Kassouf, A., El Rakwe, M., Chebib, H., Ducruet, V., Rutledge, D. and Maalouly, J. (2014) Independent Components Analysis Coupled with 3D-Front-Face Fluorescence Spectroscopy to Study the Interaction between Plastic Food Packaging and Olive Oil. Analytica Chimica Acta, 11, 14-25.

https://doi.org/10.1016/j.aca.2014.06.035

[11] Khaneghah, M.A., Shoeibi, S., Limbo, S., Hosseini, H. and Akbarirad, H. (2015) Study of the Effect of Fatty Acids Profile on Overall Migration from PET into Different Types of Oil. International Food Research Journal, 22, 1888-1893.

[12] Dabbou, S., Gharbi, I., Dabbou, S., Brahmi, F., Nakbi, A. and Hammami, M. (2011) Impact of Packaging Material and Storage Time on Olive Oil Quality. African Journal of Biotechnology, 10, 16937-16947. https://doi.org/10.5897/AJB11.880

[13] Tawfik, S.M. (2005) Interaction of Packaging Materials and Vegetable Oils: Global Migration and Oil Absorption. Journal of Food Technology, 3, 506-510.

[14] El Haouhay, N., Smaniego-Sánchez, C., Asehraou, A., Giménez-Martínez, R.J., Villalón-Mir, M. and López-García de la Serrana, H. (2018) Effects of Olive Storage and Packaging on Microbial and Fatty Acids Profiles of Olive Oil Produced in Tra- 
ditional Mills in Morocco. Journal of Materials and Environmental Science, 9, 854-863.

[15] Kadam, A., Karbowiak, A., Voilley, T. and Debeaufort, F. (2014) Techniques to Measure Sorption and Migration between Small Molecules and Packaging. A Critical Review. Journal of the Science of Food and Agriculture, 95, 1395-1407. https://doi.org/10.1002/jsfa.6872

[16] Gonzalez, R.V.S. (2013) Impact of Polylactide (PLA) on the Quality of Bio-Products in Contact. Food Engineering. PhD Thesis, AgroParisTech, Paris.

[17] Auras, R., Harte, B. and Selke, S. (2004) An Overview of Polylactides as Packaging Materials. Macromolecular Bioscience, 16, 835-864. https://doi.org/10.1002/mabi.200400043

[18] Technical Committee CEN/TC 194 (2002) Materials and Articles in Contact with Foodstuffs-Plastics Part 2: Test Methods for Overall Migration into Olive Oil by Total Immersion. Br Stand ENV 1186-2-49.

[19] EC (1991) Commission Regulation EC No 2568/91 July 11, 1991. Official EC Journal L 248 of September 5 1991, 0001-0082.

[20] EC (1997) Commission Regulation EC No 2472/97 December 12, 1997. Official EC Journal L 341 of December 12, 1997 0025-0039.

[21] Mancebo-Campos, V., Desamparados Salvador, M. and Fregapane, G. (2007) Comparative Study of VOO Behavior under Rancimat Accelerated Oxidation Conditions and Long-Term Room Temperature Storage. Journal of Agricultural and Food Chemistry, 55, 8231-8236. https://doi.org/10.1021/jf070915y

[22] Gómez-Alonso, S., Mancebo-Campos, V., Maria Desamparados Salvador, M. and Fregapane, G. (2007) Evolution of Major and Minor Components and Oxidation Indices of Virgin Olive Oil during 21 Months Storage at Room Temperature. Food Chemistry, 100, 36-42. https://doi.org/10.1016/j.foodchem.2005.09.006

[23] García-González, D.L. and Aparicio, R. (2002) Detection of Defective Virgin Olive Oil by Metal-Oxide Sensors. European Food Research and Technology, 215, 118-123. https://doi.org/10.1007/s00217-002-0527-9

[24] Grigoriadou, D. and Tsimidou, M.Z. (2006) Quality Control and Storage Studies of Virgin Olive Oil: Exploiting UV Spectrophotometry Potential. European Journal of Lipid Science and Technology, 108, 61-69. https://doi.org/10.1002/ejlt.200500204

[25] Yıldırım, G. (2009) Effect of Storage Time on Olive Oil Quality. Master's Thesis, İzmir Institute of Technology, İzmir.

[26] Pristouri, G., Badeka, A. and Kontominas, M.G. (2010) Effect of Packaging Material Headspace, Oxygen and Light Transmission, Temperature and Storage Time on Quality Characteristics of Extra Virgin Olive Oil. Food Control, 21, 412-418. https://doi.org/10.1016/j.foodcont.2009.06.019

[27] Di Serio, M.G., Giansante, L., Di Loreto, G. and Di Giacinto, L. (2018) Shelf Life of Extra Virgin Olive Oil: First Efforts toward a Prediction Model. Journal of Food Processing and Preservation, 42, e13663. https://doi.org/10.1111/jfpp.13663

[28] Beldì, G., Pastorelli, S., Franchini, F. and Simoneau, C. (2012) Time- and Temperature-Dependent Migration Studies of Irganox 1076 from Plastics into Foods and Food Simulants. Food Additives \& Contaminants. Part A, 29, 836-845. https://doi.org/10.1080/19440049.2011.649304

[29] Dopico-García, M.S., Lopez-Vilarino, J.M. and González-Rodríguez, M.V. (2007) Antioxidant Content of and Migration from Commercial Polyethylene, Polypropylene, and Polyvinyl Chloride Packages. Journal of Agricultural and Food Chemis- 
try, 55, 3225-3231. https://doi.org/10.1021/jf070102

[30] EU (2011) Commission Regulation No 10/2011 of 14 January 2011 on Plastic Materials and Articles Intended to Come into Contact with Food. Off. J. Eur. Union Comm.

https://eur-lex.europa.eu/legal-content/EN/ALL/?uri=celex\%3A32011R0010

[31] Caner, C. (2011) Sorption Phenomena in Packaged Foods: Factors Affecting Sorption Processes in Package-Product Systems. Packaging Technology and Science, 24, 259-270. https://doi.org/10.1002/pts.935

[32] Rawal, P. (2011) Comparative Performance of PLA and PET Bottles for Alcohol and Sugar Acid Solutions. Michigan State University, East Lansing.

[33] Rogers, M.E. and Long, T.E. (2003) Synthetic Methods in Step-Growth Polymers. John Wiley \& Sons, New York. https://doi.org/10.1002/0471220523

[34] Day, M., Nawaby, A. and Liao, X. (2006) A DSC Study of the Crystallization Behaviour of Polylactic Acid and Its Nanocomposites. Journal of Thermal Analysis and Calorimetry, 86, 623-629. https://doi.org/10.1007/s10973-006-7717-9

[35] Bruscatto, M.H., Zambiazi, R.C., Crizel-Cardoso, M., Piatnicki, C.M., Mendonça, C.R., Dutra, F.L. and Coutinho, E.F. (2017) Chemical Characterization and Oxidative Stability of Olive Oils Extracted from Olive Trees of Southern Brazil. Pesquisa Agropecuaria Brasileira, 52, 1231-1240.

https://doi.org/10.1590/s0100-204x2017001200012 